\title{
Dental caries and associated factors among primary school children in Bahir Dar city: a cross-sectional study
}

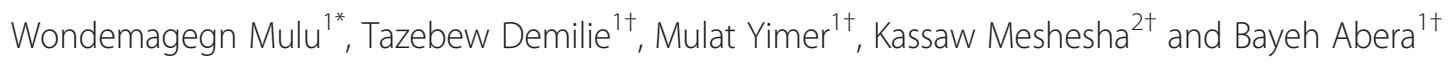

\begin{abstract}
Background: Dental caries is the most common chronic infectious disease of childhood caused by the interaction of bacteria, mainly Streptococcus mutans and sugary foods on tooth enamel. This study aimed at determining the prevalence and associated factors of dental caries among primary school children at Bahir Dar city.

Methods: A school based cross-sectional study was conducted at Bahir Dar city from October 2013 to January 2014. Systematic random sampling technique was used to select the children. Structured questionnaire was used to interview children and/or parents to collect socio demographic variables. Clinical dental information obtained by experienced dentist using dental caries criteria set by World Health Organization. Binary and multiple logistic regression analysis were computed to investigate factors associated with dental caries.

Results: Of the 147 children, 82 (55.4\%) were girls. Majority of the children (67.6\%) cleaned their teeth using traditional method (small stick of wood made of a special type of plant). The proportion of children having dental caries was 32 (21.8\%). Primary tooth decay accounted for 24 (75\%) of dental caries. The proportion of missed teeth was 7 (4.8\%). The overall proportion of toothache and dental plaque among school children were 40 (27.2\%) and $99(67.3 \%)$, respectively. Grade level of $1-4(\mathrm{AOR}=3.9, \mathrm{Cl}=1.49-10.4)$, poor habit of tooth cleaning $(\mathrm{AOR}=2.6$, $\mathrm{Cl}=1.08$ - 6.2), dental plaque (AOR=5.3, $\mathrm{Cl}=1.6-17.7)$ and toothache $(\mathrm{AOR}=6.3, \mathrm{Cl}=2.4-15.4)$ were significantly associated with dental caries.
\end{abstract}

Conclusion: Dental caries is a common public health problem in school children associated with poor oral hygiene, dietary and dental visit habits. Therefore, prevention measures such as health education on oral hygiene, dietary habits and importance of dental visit are obligatory for children.

Keywords: Dental caries, Dental plaque, Children

\section{Background}

Dental caries is the most prevalent and chronic oral disease particularly in childhood age [1,2]. Dental caries is a progressive infectious process with a multifactorial etiology $[3,4]$. Dietary habits, oral microorganisms that ferment sugars, and host susceptibility have to coexist for dental caries to initiate and develop [3-5]. Dental caries

\footnotetext{
*Correspondence: Wondem_32@yahoo.com

${ }^{\dagger}$ Equal contributors

'Department of Medical Microbiology, Immunology and Parasitology, College of Medicine and Health Sciences, Bahir Dar University, Bahir Dar, Ethiopia

Full list of author information is available at the end of the article
}

has high morbidity potential. Thus, it has been the main focus of dental health professionals [6].

Dental caries is caused by dental plaque deposits on the tooth surface $[7,8]$. After intake of fermentable carbohydrates, Streptococcus mutans undergo fermentation and produce copious amount of acid and lowers the local $\mathrm{pH}$ to a level where the minerals of enamel and dentine dissolve [3,5,7-11]. The frequent intake of sweets, dry mouth, and poor oral hygiene increase the chances for cavities $[8,12]$.

Dental caries causes teeth pain, discomfort, eating impairment, loss of tooth and delay language development. Furthermore, dental caries has effects on childern's concentration in school and a financial burden on the

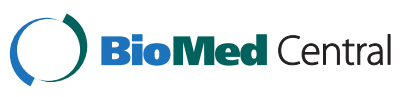


families [6,13]. Risk factors such as sex, age, dietary habits, socioeconomic and oral hygiene status are associated with increased prevalence and incidence of dental caries in a population [14].

Although, the trend is not clear in developing countries, the burden of dental caries has been increasing among children due to the unlimited consumption of sugary substances, poor oral care practices and inadequate health service utilization [15]. Studies revealed that the prevalence of dental caries was higher among urban children $[14,16]$. Similarly, a study conducted in Ethiopia was reported $36.5 \%$ prevalence of dental caries among urban children in school [8]. Although, dental caries is more prevalent in school children, there was no documented data on prevailing prevalence and associated factors in primary school children in Bahir Dar city. Therefore, the present study was carried out to determine the prevalence and associated factors of dental caries among primary school children.

\section{Methods}

\section{Study design and area}

A school based cross-sectional study was conducted from October 2013 to January 2014 among primary school children at Bahir Dar city. Bahir Dar city is 560 kilometers away from the capital city, Addis Ababa. According to 2011 Central Statistical Agency of Ethiopia (CSA) estimates, the city has a total population of 220,344. Urban primary school children under 16 years accounted for 27,511 . Of these, 20,340 were from public schools. The town has a total of 35 urban primary schools. Of these, 22 were private and the rest 13 were public schools [17].

\section{Study participants}

Children from primary schools between 6 to 15 years of age and living at Bahir Dar city were included in the study. Children with 16 years of age and above, and those from private schools were excluded from the study.

\section{Sample size and sampling}

Sample size was calculated using single population proportion formula with an assumption of $95 \%$ confidency level, $7 \%$ degree of precision and proportion of dental caries, $36.5 \%$ [8] to make the final sample size of 180 . However, only 147 students provided a complete response. Systematic random sampling technique was employed to select the study participants. Among thirteen government schools, three were selected using systematic random sampling technique. The sample size was allocated proportionally based on the number of children in each selected school. Children were selected randomly based on their name lists taken from their rosters in respective class.

\section{Data collection}

A structured questionnaire was used to collect sociodemographic characteristics, dietary habits, oral health problems and oral care practices. Dental examination was carried out for all selected children by one trained dental doctor using World Health Organization (WHO) dental caries diagnosis guide line under natural day light [15]. Disposable wooden spatulas were used for intraoral examination. Prior to the study, data collectors were given for two days intensive training on dental caries assessment based on WHO guide line and on how to interview children and fill the questionnaire. Incomplete questionnaires were rejected during data analysis. Dental caries was recorded as being present when a lesion in a pit or fissure or on smooth tooth surface had a detectable softened floor, undermined enamel or softened wall. When any doubt existed, dental caries was not recorded as present. Tooth was considered missing because of caries if a person gave a history of pain and/or presence of cavity prior to extraction.

The presence of dental plaque was assessed by direct visual inspection and palpation of the buccal and lingual surfaces of all teeth with clean glove and spatula [18]. Plaque was recorded as being present when visible deposits were detected and then removed following palpation of the teeth by clean gloved hand. Moreover, the presence of both hypo calcification and incipient caries type of white spot lesions were examined by conventional diagnostic technique [18]. First, the wet teeth were inspected for the presence of hypo calcification type of white spot lesion then the teeth were allowed to wipe cleaned and dried with gauze and compressed air to inspect incipient caries type of white spot lesion. White spot lesion was recorded as being present when a white chalky appearance spot were revealed either in dehydrated or desiccated or both type of the upper and lower anterior of enamel.

\section{Data analysis}

Data was entered and analyzed using statistical package for social science (SPSS) version 20. Frequency and percentage were computed from univariate analysis to get summary values. Odds ratio with $95 \%$ confidence interval (CI) was computed using logistic regression analysis to assess the presence and degree of association between dental caries and independent variables. Significance was set at $\mathrm{p}<0.05$ (significance level 95\%). For those variables that had a p-value $<0.05$ on binary logistic regression, binary multiple logistic regression analysis was computed.

\section{Ethical considerations}

Ethical clearance was obtained from ethical review committee of College of Medicine and Health Sciences, Bahir Dar University. A written consent was obtained from 
children's parents before interview and dental examination. Cases of dental caries were advised to attend the nearby dental clinic.

\section{Results}

Sociodemographic characteristics

A total of 147 children were participated in the study. Of these, $82(55.4 \%)$ were girls. The majority of children (69.6\%) were from 11 to 15 years of age. Nearly half of the study participants were grade $1-4$. Twenty one (14\%) of the students' parent had an education above grade 12 . Eighty (54.1\%) of the participants family earned below 1000 Ethiopian birr per month (Table 1).

\section{Food consumption pattern, dietary habits and practices} related to oral hygiene

One hundred four $(70.7 \%)$ of the children had breakfast bread with tea. Most of the children (85\%) usually drank tea with sugar. Thirty one (21.1\%) of the participants drank coffee with sugar. Fifty five (37.4\%) of the children drank soft drinks. Seventy one, $(48.3 \%)$ of the children used to eat sweet foods. One hundred five (71.4\%) of the children were used to clean their teeth. Of whom, 16 (15.2\%) cleaned their teeth before and after meal.
However, nearly half of the children cleaned their teeth only after meal intake. Majority of the children (67.6\%) used a traditional small stick of wood (termed as Mafaqiya) made of a special type of plant to clean their teeth. However, 18 (9.5\%) and 5 (4.8\%) were used teeth brush with and without paste, respectively to clean their teeth (Table 2).

\section{Dental caries}

Of the 147 study participants, 32 (21.8\%) had decayed tooth. The proportion of dental caries was $33.3 \%$ in children from 6 to 10 years of age. Girls were with a higher proportion of dental caries $(24.4 \%)$ than boys $(18.5 \%)$. However, the difference was not statistically significant $(\mathrm{P}=0.87)$. The proportion of dental caries was 23 (31.9\%) and 9 (12.2\%) among children from grade1- 4 and 5-8, respectively. Children belonging to the lowest income group had the highest proportion of dental caries but the highest income group had higher prevalence than the middle income group (Table 1). Among the total dental caries, the majority 24. (75\%) had primary tooth decay. Of the children who had dental caries, $12(50 \%)$ had more than one affected tooth and 7 (21.9\%) revealed missed teeth. Toothache and white spot lesions were found in 40 (27.2\%) and 12 (8.2\%) of children, respectively.

Table 1 Prevalence of dental caries and socio-demographic characteristics among primary school children at Bahir Dar city, 2014 ( $n=147$ )

\begin{tabular}{|c|c|c|c|c|c|}
\hline \multirow[t]{2}{*}{ Socio-demographic variables } & \multicolumn{3}{|c|}{ Dental carries } & \multirow[t]{2}{*}{ COR $(95 \% \mathrm{Cl})$} & \multirow[t]{2}{*}{ P-value } \\
\hline & Positive N (\%) & Negative N (\%) & Total N (\%) & & \\
\hline \multicolumn{6}{|l|}{ Age in years } \\
\hline $6-10$ & $15(33.3)$ & $30(66.7)$ & $45(30.4)$ & $0.4(0.18-1.0)$ & 0.03 \\
\hline $11-15$ & $17(16.7)$ & $85(83.3)$ & $102(69.6$ & 1 & \\
\hline \multicolumn{6}{|l|}{ Sex } \\
\hline Boys & $12(18.5)$ & $53(81.5)$ & $65(44.6)$ & 1 & \\
\hline Girls & $20(24.4)$ & $62(75.6)$ & $82(55.4)$ & $0.7(0.31-1.57)$ & 0.87 \\
\hline \multicolumn{6}{|l|}{ Grade } \\
\hline $1-4$ & $23(31.9)$ & $49(68.1)$ & $72(49)$ & $0.26(0.07-0.92)$ & 0.03 \\
\hline 5- 8 & $9(12.2)$ & $65(87.8)$ & $75(51)$ & 1 & \\
\hline \multicolumn{6}{|l|}{ Family income } \\
\hline$<1000$ & $21(26.3)$ & $59(73.8)$ & $80(54.1)$ & $0.23(0.07-0.72)$ & 0.2 \\
\hline $1001-2000$ & $5(11.9)$ & $37(88.1)$ & $42(28.4)$ & $0.24(0.63-8.66)$ & 0.82 \\
\hline$>2000$ & $6(24)$ & $19(76)$ & $25(17.6)$ & 1 & \\
\hline \multicolumn{6}{|l|}{ Family educational status } \\
\hline Illiterate & $10(18.5)$ & $44(81.5)$ & $54(36.7)$ & & \\
\hline Can read and write & $7(38.9)$ & $11(61.1)$ & $18(12.2)$ & & 0.03 \\
\hline 1-8 grade level & $7(31.8)$ & $15(68.2)$ & $22(15)$ & & \\
\hline 9-12 grade level & $8(25)$ & $24(75)$ & $32(21.8)$ & & \\
\hline$>12$ grade level & 0 & $21(100)$ & $21(14.3)$ & & \\
\hline Total & $32(21.8)$ & $115(78.2)$ & $147(100)$ & & \\
\hline
\end{tabular}

Key: COR (crude odds ratio), Cl (Confidence interval), ' (Reference category). 
Table 2 Food consumption pattern, dietary habits and practices of oral hygiene among primary school children at Bahir Dar city, 2014

\begin{tabular}{|c|c|c|c|c|}
\hline \multirow[t]{2}{*}{ Variables } & \multicolumn{2}{|c|}{ Dental caries } & \multirow[b]{2}{*}{ Total } & \multirow[t]{2}{*}{ P-value } \\
\hline & Positive N (\%) & Negative $\mathrm{N}(\%)$ & & \\
\hline \multicolumn{5}{|c|}{ Consumption of sugared tea $(n=147)$} \\
\hline Yes & $26(20.8)$ & $99(79.2)$ & $125(85)$ & \multirow[t]{2}{*}{0.33} \\
\hline No & $6(27.3)$ & $16(72.7)$ & $22(15)$ & \\
\hline \multicolumn{5}{|c|}{ Consumption of sugared coffee $(n=147)$} \\
\hline Yes & $6(19.4)$ & $25(80.6)$ & $31(21.1)$ & \multirow[t]{2}{*}{0.81} \\
\hline No & $26(22.6)$ & $90(73.4)$ & $116(78.9)$ & \\
\hline \multicolumn{5}{|l|}{ Type of food for breakfast $(n=147)$} \\
\hline Bread with tea & $24(23.1)$ & $80(76.9)$ & $104(70.7)$ & \multirow[t]{3}{*}{0.47} \\
\hline Pasta & $7(21.1)$ & $28(78.8)$ & $35(23.8)$ & \\
\hline Other (Makorony, Rice) & 0 & 8 & $8(5.4)$ & \\
\hline \multicolumn{5}{|c|}{ Consumption of sweet foods $(n=147)$} \\
\hline Yes & $21(29.6)$ & $50(70.4)$ & $71(48.3)$ & \multirow[t]{2}{*}{0.03} \\
\hline No & $11(14.7)$ & $64(85.3)$ & $76(51.7)$ & \\
\hline \multicolumn{5}{|l|}{ Consumption of soft drinks $(n=147)$} \\
\hline Yes & $15(27.3)$ & $40(72.7)$ & $55(37.4)$ & \multirow[t]{2}{*}{0.21} \\
\hline No & $17(18.5)$ & $75(81.5)$ & $92(62.6)$ & \\
\hline \multicolumn{5}{|c|}{ Frequency of taking soft drinks $(n=55)$} \\
\hline$<4 /$ day & $11(22)$ & $39(76.5)$ & $50(91.1)$ & \multirow[t]{2}{*}{0.02} \\
\hline$>4 /$ day & $3(75)$ & $1(25)$ & $5(7.3)$ & \\
\hline \multicolumn{5}{|l|}{ Cleaning teeth $(n=147)$} \\
\hline Yes & $17(16)$ & $88(84)$ & $105(71.4)$ & \multirow[t]{2}{*}{0.016} \\
\hline No & 15 (36.6) & $26(63.4)$ & $41(27.9)$ & \\
\hline \multicolumn{5}{|l|}{ Time of tooth cleaning $(n=105)$} \\
\hline Before meal & $5(16.7)$ & $25(83.3)$ & $30(28.6)$ & \multirow[t]{4}{*}{0.63} \\
\hline After meal & $7(13.2)$ & $46(86.8)$ & $53(50.5)$ & \\
\hline Before and after meal & $3(18.8)$ & $13(81.2)$ & $16(15.2)$ & \\
\hline No fixed time & $2(33.3)$ & $4(66.7)$ & $6(5.7)$ & \\
\hline \multicolumn{5}{|l|}{ Way of cleaning teeth $(n=105)$} \\
\hline Tooth stick & $10(14.1)$ & $61(85.9)$ & $71(67.6)$ & \multirow[t]{6}{*}{0.52} \\
\hline Tooth brush without paste & 0 & 5 & $5(4.8)$ & \\
\hline Tooth brush with paste & $5(27.8)$ & 13(72.2) & $18(9.5)$ & \\
\hline Charcoal & 0 & 1 & $1(0.96)$ & \\
\hline Rinse with water & $1(25)$ & $3(75)$ & $4(3.8)$ & \\
\hline Other means & $1(16.7)$ & $5(83.3)$ & $6(5.7)$ & \\
\hline
\end{tabular}

Key: N (number), \% (percent).

However, dental plaque was clinically visible in 99 (67.3\%) of the children. To get treatment for dental caries, 9 children (6.1\%) had consulted a dentist (Table 3).

\section{Risk factors associated with dental caries}

Based on bivariate analysis, significant association between dental caries and educational status of children's parents was found $(P=0.03)$. Dental caries among children, whose parents' education are above grade 12 were $100 \%$ times at a lower risk compared to those who had non-educated parents (Table 1). There was significant association between dental caries and grade levels of children (AOR = $3.9,95 \% \mathrm{CI}=1.49$ - 10.4). Children whose grade level $1-4$ were more likely to have dental caries compared to grade level of $5-8$. Children who did not clean their teeth were 2.6 times more likely to have caries than those who 
Table 3 Dental cases of primary school children aged 6-15 years, at Bahir Dar city, 2014

\begin{tabular}{|c|c|c|}
\hline Variables & Frequency & Percent \\
\hline \multicolumn{3}{|c|}{ Tooth decay/dental caries (any type) $(n=147)$} \\
\hline Yes & 32 & 21.8 \\
\hline No & 115 & 78.2 \\
\hline \multicolumn{3}{|l|}{ Type of tooth decayed $(n=32)$} \\
\hline Decay of primary tooth & 24 & 75 \\
\hline Decay of permanent tooth & 8 & 25 \\
\hline \multicolumn{3}{|c|}{ Number of primary teeth decay $(n=32)$} \\
\hline 1 tooth & 12 & 50 \\
\hline 2 teeth & 6 & 25 \\
\hline 3 teeth & 5 & 20.8 \\
\hline 4 teeth & 1 & 4.2 \\
\hline \multicolumn{3}{|l|}{ Type of missed teeth $(n=7)$} \\
\hline Primary & 5 & 71.4 \\
\hline Permanent & 2 & 28.6 \\
\hline \multicolumn{3}{|l|}{ Tooth ache $(n=147)$} \\
\hline Yes & 40 & 27.2 \\
\hline No & 107 & 72.8 \\
\hline \multicolumn{3}{|l|}{ White spot lesions $(n=147)$} \\
\hline Yes & 12 & 8.2 \\
\hline No & 135 & 91.8 \\
\hline \multicolumn{3}{|l|}{ Plaque accumulation $(n=147)$} \\
\hline Yes & 99 & 67.3 \\
\hline No & 48 & 32.7 \\
\hline \multicolumn{3}{|c|}{ Health institution / Dental visit $(n=147)$} \\
\hline Yes & 9 & 6.1 \\
\hline No & 138 & 93.9 \\
\hline
\end{tabular}

cleaned $(\mathrm{AOR}=2.6,95 \% \mathrm{CI}=1.08$ - 6.2). Children who had dental plaque were 5.3 times more likely to have dental caries than those who had not $(\mathrm{AOR}=5.3,95 \% \mathrm{C} \mathrm{I}=1.6-$ 17.7). Moreover, the odds of having dental caries was significantly higher among children suffer with tooth ache than those children who had not $(\mathrm{AOR}=6.3,95 \% \mathrm{CI}=2.4-15.4)$ (Table 4).

\section{Discussion}

In Ethiopia, there is scarcity of data on dental caries in primary school children. In this study, dental caries is a common health problem among primary school children. The prevalence of dental caries found in the present study was comparable with a study conducted in Tanzania (17.6\%) [19]. However, it was lower than studies carried out in other parts of Ethiopia (36.3- 48.1\%) [8,20], Nigeria (35.5\%) [1], Nepal (52\%) [21] and India (77\%) [22]. The difference could be due to difference in knowledge, attitude and practices (KAPs) on oral hygiene as our study was under taken among urban school children. In addition, the lower sample size in the present study might be accounted for the difference.

As a result of shortage of dental insurance and families lacking usual source of dental care, previous studies have shown that children living in poverty have higher prevalence of dental caries $[7,23,24]$ but in this study a clear association between family income and dental caries was not observed. This was comparable with a study done in Sirilanka [23]. Though, the lowest income group had highest prevalence of dental caries, the middle income group had lower prevalence than the highest income group. This discrepancy might be due to other confounding factors like dietary habits.

Children's grade level was found to be statistically significant for dental caries, hence as their grade levels increased the chance of dental caries get reduced. This finding was also supported by similar findings [8,25,26]. On bivariate analysis, habit of consumption of sweet foods has significantly associated with dental caries. This finding was in agreement with a study done in Saudi Arabia [5]. 
Table 4 Factors associated with dental caries in primary school children at Bahir Dar city, 2014

\begin{tabular}{|c|c|c|c|c|c|}
\hline \multirow[t]{2}{*}{ Characteristics } & \multicolumn{2}{|c|}{ Dental caries } & \multirow[t]{2}{*}{ COR $(95 \% \mathrm{Cl})$} & \multirow[t]{2}{*}{ AOR $(95 \% \mathrm{Cl})$} & \multirow[t]{2}{*}{ P-value } \\
\hline & Yes & No & & & \\
\hline \multicolumn{6}{|l|}{ Age in years } \\
\hline $6-10$ & 15 & 30 & $0.4(0.18-0.89)^{* *}$ & $0.62(0.2-1.92)$ & 0.62 \\
\hline 11-15 & 17 & 85 & 1 & 1 & \\
\hline \multicolumn{6}{|l|}{ Grade level } \\
\hline $1-4$ & 23 & 50 & $0.3\left(0.13-0.71^{* *}\right.$ & $3.9(1.49-10.4)$ & 0.006 \\
\hline 5- 8 & 9 & 65 & 1 & 1 & \\
\hline \multicolumn{6}{|l|}{ Cleaning teeth } \\
\hline Yes & 17 & 89 & 1 & 1 & \\
\hline No & 15 & 26 & $0.35(0.15-0.79)^{* *}$ & $2.6(1.08-6.2)$ & 0.033 \\
\hline \multicolumn{6}{|c|}{ Use of sweet foods } \\
\hline Yes & 21 & 50 & $0.4(0.18-0.91)^{* *}$ & $0.46(0.18-1.16)$ & 0.09 \\
\hline No & 11 & 65 & 1 & 1 & \\
\hline \multicolumn{6}{|l|}{ Tooth ache } \\
\hline Yes & 17 & 23 & $4.5(1.97-10.41)^{* * *}$ & $6.3(2.4-15.4)$ & $<0.001$ \\
\hline No & 15 & 92 & 1 & 1 & \\
\hline \multicolumn{6}{|c|}{ Plague accumulation } \\
\hline Yes & 28 & 71 & $4.3(1.43-13.2)^{* *}$ & $5.3(1.6-17.7)$ & 0.006 \\
\hline No & 4 & 4 & 1 & 1 & \\
\hline
\end{tabular}

Key: COR (Crude odds ratio), AOR (adjusted odds ratio), $\mathrm{Cl}$ (Confidence interval). **:P-value $<0.05,{ }^{* * *}: 0.05<$ P-value $<0.001$.

This might be associated with copious acid production by cariogenic bacteria like Streptococcus mutans that are adherent to teeth as a result of fermentation of the sweet foods. Later the enamel of the tooth went into tooth decay $[5,26]$. Moreover, poor habit of tooth cleaning was significantly associated with dental caries. Children who had cleaned their teeth revealed a lower prevalence of dental caries. It is generally true that cleaning teeth will remove away the food debris from the oral. Therefore, Streptococcus mutans cannot get enough nutrient and time for growth and no acid production that causes dental caries development $[18,26]$.

It is known that toothache is one of the major indicators of tooth decay $[18,27]$. In this study, children who had toothache were 6.3 times more likely to have dental caries. This finding conforms to a study conducted in Dare Salaam [27]. Moreover, dental plaque was significantly associated with dental caries. Children having visible dental plaque were more likely to have dental caries than their free counter parts. This is also a good indicator of poor oral hygiene practices. Because, dental plaque retention increases Streptococcus mutans colonization and in severe cases, the loss of enamel. In other studies, children with visible dental plaque recognized as a proxy of poor tooth brushing frequency. Similar finding was reported in Tanzania [19] stating that poor oral hygiene practice was the associated factor of dental carries. Moreover, such associations were established in other studies [28,29].

This study reported that $67.6 \%$ of children cleaned their teeth using traditional small stick of wood (Mafaqiya) for maintaining oral hygiene. In contrast, other studies showed that tooth brush and tooth paste were the most common means of maintaining oral hygiene $[8,21]$. In this study, a large proportion of children had never visit to a dentist. Similar finding was reported in Ethiopia [8], Nepal [21] and Sirilanka [23].

This study has the following main limitations: Detection of dental caries using dental mirror and radiology was not possible because of lack of instruments and laboratory set up. Therefore, dental caries was identified only with clinical diagnosis. In addition, the number of study participants was lower compared to other studies. Thus, this might reduce the true magnitude of the problem.

\section{Conclusion}

Dental caries is a common public health problem among primary school children at Bahir Dar city. Low grade level, poor oral hygiene and dietary along with lack of dental visit were the associated factors for dental caries. Therefore, health education on oral hygiene, dietary habits and dental visit should be given for children to prevent and 
control dental caries. Moreover, further studies including private and rural school children using all methods of diagnosis of dental caries and assessment of knowledge, attitude and practices of children and their parents on oral hygiene should be recommended.

\section{Competing interests}

The authors declare that they have no competing interests.

\section{Authors' contributions}

WM Designed the study, reviewed the questionnaires, analyzed data and wrote the article TD designed the study and collected the data BA designed the study, reviewed the questionnaires and critically edited the manuscript MY critically reviewed the manuscript KM collected the data and reviewed the manuscript. All authors read and approved the final manuscript.

\section{Authors' information}

WM is an assistant professor at College of Medicine and Health Sciences, Bahir Dar University in Medical Microbiology, BA is an associate professor at college of Medicine and Health Sciences, Bahir Dar University in Medical Microbiology and department head of Medical Microbiology, Immunology and Parasitology, MY is an assistant professor at College of Medicine and Health Sciences, Bahir Dar University in Medical Parasitology. KM is lecturer at college of Medicine and Health Sciences, Bahir Dar University in doctor of dentistry.

\section{Acknowledgments}

The study was funded by Bahir Dar University. We would like to thank all parents and children who were participated in the study. Our appreciation goes to Bahir Dar city primary school directors for their assistance and permission to conduct this study.

\section{Author details}

'Department of Medical Microbiology, Immunology and Parasitology, College of Medicine and Health Sciences, Bahir Dar University, Bahir Dar, Ethiopia. ${ }^{2}$ Department of Dentistry, College of Medicine and Health Sciences, Bahir Dar University, Bahir Dar, Ethiopia.

Received: 9 June 2014 Accepted: 17 December 2014 Published: 23 December 2014

\section{References}

1. Okoye LO, Ekwueme OC: Prevalence of Dental Caries in a Nigerian Rural Community: A Preliminary Local Survey. Ann Med Health Sci Res 2011, 1:187-196.

2. Dawkins E, Michimi A, Ellis-Griffith G, Peterson T, Carter D, English G: Dental caries among children visiting a moble dental clinic in south central Kentucky: a pooled cross-sectional study. BMC Oral Health 2013, 13:19. doi:10.1186/1472-6831-13-19.

3. Franco FE, Amoroso P, Marin JM, Ávila FA: Detection of Streptococcus mutans and Streptococcus sobrinus in dental plaque samples from Brazilian preschool children by Polymerase Chain Reaction. Braz Dent J 2007, 18:329-333.

4. Garcla-Closa R, Garcla-Closas M, Serra-Majem L: A cross-sectional study of dental caries, intake of confectioneryand foods rich in starch and sugars, and salivary counts of Streptococcus mutans in children in Spain. Am J Clin Nutr 1997, 66:1257-1263.

5. Colak H, Corul T, Dulgergi CT, Dalli M, Hamidi MM: Early child hood caries update: A review of causes, diagnosis and treatments. J Nat Sci BiOl Med 2013, 4:29-38.

6. Moses J, Rangeeth BN, Gurunathan D: Prevalence of dental caries, socioeconomic old school going children of chid ambaram status and treatment needs among 5 to 15 year old school going children Of Chidambaram. J Clin Dign Res 2011, 5:146-151.

7. Maher R, Rahimtoola S, Khan A, Bratthall D: Prevalence of mutans streptococci and dental caries in pakistani children. J Pak Med Assoc 1992, 42:213-215.

8. Ayele FA, Taye BW, Ayele TA, Gelaye KA: Predictors of dental caries among children 7-14 years old in Northwest Ethiopia: a community based crosssectional study. BMC Oral Health 2013, 13:7. doi:10.1186/1472-6831-13-7.
9. Tinanoff N, Michael MS, Kanellis MJ, Vargas CM: Current understanding of the epidemiology, mechanisms, and prevention of dental caries in preschool children. Pediatr Dent 2002, 24:543-551.

10. Amoroso P, Ávila FA, Gagliardi CM: Prevalence of different Streptococci species in the oral cavity of children and adolescents. Braz J Oral Sci 2003, 2:164-168.

11. Okada M, Soda Y, Hayashi F: Longitudinal study of dental caries incidence associated with Streptococcus mutans and Streptococcus sobrinus in pre-school children. J Med Microbiol 2005, 54:661-665.

12. Ritter AV: Dental caries talking with Patients. J Esthet Restor Dent 2004, $16: 76$.

13. Zhang S, Liu J, Lo EC, Chu C: Dental caries status of Bulang preschool children in Southwest China. BMC Oral Health 2014, 14:2-7.

14. Okoye LO: Caries experience among school children in South-Eastern Nigeria. Caries Res 2010, 44:171.

15. World Health Organization: Prevention Methods and Program for Oral Diseases WHO Technical Report Series 713. Geneva: WHO; 1984

16. Udoye Cl, Aguwa E, Chukezie R, Ezeokenwa M, Jerry-Oji O, Okpaji C: Prevalence and distribution of caries in the 12-15-year urban school children in Enugu, Nigeria. J Dent Sci 2009, 7(2). Available at https://ispub.com/JDS/7/2/11893.

17. Federal Democratic Republic of Ethiopia population census commission: Summary and statistical report of the 2007 population and Housing Census: population size by age and sex. Addis Ababa: central statistics agency; 2011.

18. Roberson TM, Heymann HO, Swift EJ: Sturdevants the art and science of operative dentistry. 4th edition. 2000:66-132.

19. Masumo R, Bardsen A, Mashoto K, Astrom AN: Prevalence and school behavioural influence of early child hood caries, ECC, and feeding habits among 6-36 months. Old children in Uganada and Tanzania. BMC Oral Health 2012, 12:24.

20. Okubagze J: Epidemiology of Dental Caries in a rural High land community North West Ethiopia. Ethiop Med J 1987, 25:127.

21. Dixit LP, Shakya A, Shrestha M, Shrestha A: Dental caries prevalence, oral health knowledge and practice among indigenous chepang school children of Nepal. BMC Oral Health 2013, 13:20. doi:10.1186/1472-6831-13-20.

22. Joshi N, Rajesh R, Sunitha M: Prevalence of dental caries among school children in Kulasekharam village: a correlated prevalence survey. J Indian Soc Pedod Prev Dent 2005, 3(3):138-140.

23. Perpera P, Abeyweera NT, Fernando MP, Warnakulasuriya TD, Ranthunga N: Prevalence of dental caries among a cohort of preschool children living in Gamaha district, Srilanka: a descriptive cross sectional study. BMC Oral Health 2012, 12:49.

24. AJ-Jewair TS, Leake JL: The prevalence and risks of early child hood caries in Toronto, canda. J Contemp Dent Pract 2010, 11:1-8.

25. Masson LH, Blackburn GA, Sheery C, Caig LC: Sugar intake and dental decay; results from a survey of children in Scotland. Br J Nutr 2010, 104:1555-1564.

26. Dawani N, Nisar N, Khan N, Syed S, Tanweer N: Prevalence and factors related to dental caries among pre-school children of sadder town, Karachi, Pakistan: across-sectional study. BMC Oral Health 2012, 12:59.

27. Maro D, Roberst H, Machibya F, Kahabuka K, Mugonzibwa EA: Previous toothache, dental visits and caries presence among primary school children in Dares Salam. Tan Dent J 2012, 17:(2). Available at www.ajol.info/ index.php/tdj/article/view/8545.

28. Declerk D, Leroy R, Martensh Lesaffre E: Factors associated with prevalence and severity of caries experience in preschool children. Community Dental Oral Epidemiol 2008, 36:168-178.

29. Paw TR: Dental health status and caries pattern of preschool children in Al-kharJ. Saudi Arabia Saudi Med J 2003, 24:1347-1351.

doi:10.1186/1756-0500-7-949

Cite this article as: Mulu et al: Dental caries and associated factors among primary school children in Bahir Dar city: a cross-sectional study. BMC Research Notes 2014 7:949. 